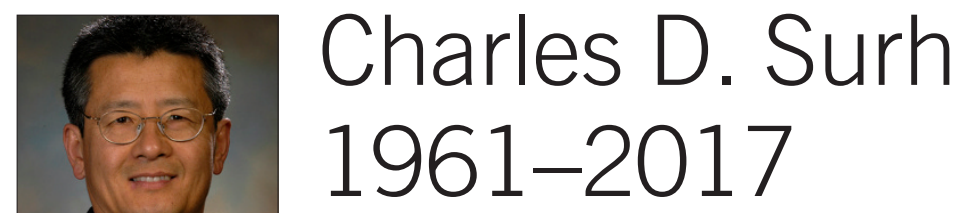

Janko Nikolich-Žugich

Talking about a close friend's passing is painful. If that friend is an exceptional human being, a beloved colleague, and an outstanding scientist, the pain only intensifies. It is only the chuckles and laughs experienced together that cheer us up for a moment when they flash in the memory, and help us transcend sorrow to celebrate the life of the one we want to keep permanently in our hearts and minds.

Charlie Surh left us in early October, way too early, after a heroic two-and-a-half-year battle with cancer. He was a giant in immunology, a tremendous intellect and a genuinely wonderful human being. Yet it will always be the memories of Charlie's infectious laughter and great sense of humor that bring joy and delight to those who knew him. By all that, Charlie Surh should be immortal.

I met Charlie in 1989, when he joined Jon Sprent's lab at the Scripps Clinic and Research Foundation (now TSRI) as a research associate. I was a postdoc with Mike Bevan. The Sprent and Bevan labs occupied adjacent modules of a contiguous space, with no doors to separate them. For T cell immunologists, the times were historic-between 1983 and 1990, T cell receptors (TCRs) were cloned, mechanisms of antigen processing and presentation began to emerge, we got the first crystal structures of peptide-MHC complexes, and the first TCR-transgenic mice helped scientists elucidate intrathymic positive and negative selection at the single-receptor level. These findings, our outstanding mentors, and the strong communication between the Sprent and Bevan labs all exerted a formative influence on many of us trainees. Charlie epitomized this by bringing always relevant and elegant in vivo approaches to the cutting-edge questions in T cell biology. From there, he never stopped discovering new information about the $\mathrm{T}$ cell production and maintenance factory.

Charlie remained at Scripps for 23 years, advancing through the ranks to professor, before returning to his native Korea to serve as professor in the Department of Integrative Biosciences \& Biotechnology and director of the Academy of Immunology and Microbiology, both at Pohang University. He also maintained an active laboratory at the La Jolla Institute of Allergy and Immunology.

During both his postdoc training and his long-term collaboration with Jon Sprent, Charlie contributed major findings to our understanding of T cell development. He discovered distinct subsets of thymic medullary cells with different roles in tolerance induction and showed that their growth is controlled by mature T cells. He and Sprent resolved a long-standing conundrum about how $>95 \%$ of thymocytes can be dying at any given point without evidence of a 'thymocyte graveyard'. They showed that immature thymocytes mostly die from a lack of positive selection and are rapidly removed by thymic phagocytes. Shortly afterward, Charlie documented peptide-related specificity in positive intrathymic selection of $\mathrm{CD} 4^{+} \mathrm{T}$ cells.

However, Charlie's most important papers—-true tours de force-elucidated the maintenance and homeostasis of peripheral T cells. In 1999, he showed that the maintenance of peripheral $\mathrm{T}$ cells critically depends on subthreshold TCR signals received from the peptide-MHC (pMHC) complexes that mediated positive selection of that TCR in the thymus. In several landmark publications he then documented that both homeostatic maintenance and lymphopenia-induced proliferation are controlled by various combinations of self-pMHC ligands and the cytokines IL-7 and IL-15. In collaboration with Sprent, he translated these findings to immunotherapy by using cytokine-anti-cytokine complexes, paving the way for the upcoming large animal preclinical and clinical trials. He then broke open another field by showing that the gut microbiome and dietary antigens can decisively influence the homeostasis and function of T cells. In all, he made enough seminal discoveries for several lifetimes.

Yet this summary does little justice to the immeasurable impact that he made via his trainees and colleagues. There is no metric to describe Charlie's friendship, no Nature paper that can possibly capture the generosity of his heart. Those of us who knew him well will celebrate that, as well as everything else he has left to us, for life. We will do that alongside his angel wife Helen, who nursed him every day, and his wonderful children Nicolette, Christopher, and Natalie, who gave him all their love and support.

Perhaps the best description of what Charlie meant to his friends was rendered by his oldest daughter, Nicolette. In her mid-teens, Nicolette had the (mis)fortune to spend one ThymOZ meeting among the thymus/T cell crowd on Heron Island in Australia. On the second day of the conference, she called her mom, Helen, from a payphone on the island and said in the most horrified teen I-am-sooo-embarrassed-bythese-adults voice, "Mom, I met Dad's friends. They're just like Dad!!!” And to me, that was one of the highest compliments I have ever received. I am repeating it to myself now, to chase away the sorrow, to make myself smile, and to wish my friend safe travels and many pleasant journeys through the heavenly $\mathrm{T}$ cell factory. 


\section{Author Correction: Charles D. Surh 1960-2017}

Janko Nikolich-Žugich

Correction to: Nature Immunology 18, 1273 (2017); published online 16 November 2017.

In the version of this article initially published, the year of birth provided (1960) was incorrect. The correct year is 1961 . The error has been corrected in the HTML and PDF versions of the article. 